\title{
Osmotic demyelination syndrome following slow correction of hyponatremia: Possible role of hypokalemia
}

\author{
Parvaiz A. Koul, Umar Hafiz Khan, Rafi A. Jan, Sanaullah Shah, Abdul Baseer Qadri, Burhan \\ Wani, Mohammed Ashraf, Feroze Ahmad, Sajjad R. Bazaz
}

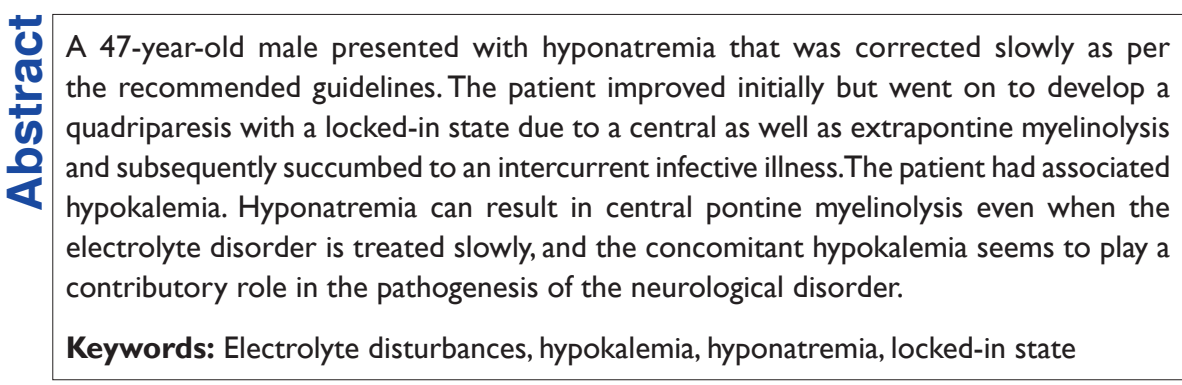

\section{Introduction}

Rapid correction of hyponatremia is a known risk factor for the development of osmotic demyelination syndrome (ODS), ${ }^{[1]}$ a disorder characterized by the wide spread development of demyelination in the pontine as well as the extra-pontine regions. However, even slow correction of hyponatremia can result in ODS. We herewith describe a patient of ODS in the face of a slow correction of hyponatremia and associated hypokalemia.

\section{Case Report}

A 47-year-old non-alcoholic male presented to the ER with altered sensorium. One week earlier, he had been started on ofloxacin for a lower urinary infection, following which he developed oliguria and swelling of whole body. On examination, he had pedal edema, facial puffiness, and mild hypertension $(146 / 92 \mathrm{mmHg})$. Urine

From:

Department of Internal and Pulmonary Medicine, SheriKashmir Institute of Medical Sciences, Srinagar, Kashmir, India

\section{Correspondence:}

Prof. Parvaiz A Koul, Department of Internal and Pulmonary Medicine, Sheri Kashmir Institute of Medical Sciences, Soura, Srinagar - 190 011, Kashmir, India.

E-mail: parvaizk@gmail.com

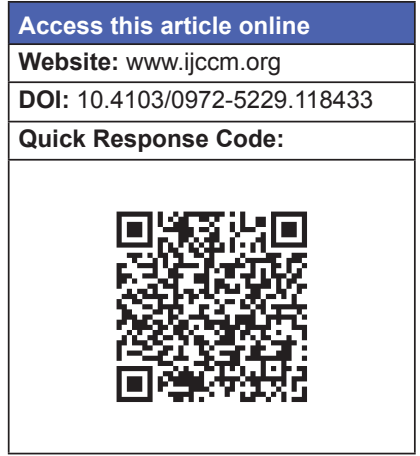

examination revealed a protein $100 \mathrm{mg} / \mathrm{dl}, 18-20 \mathrm{WBC}$, and 2-4 RBC per HPF. Serum creatinine was $1.8 \mathrm{mg} / \mathrm{dl}$, and a diagnosis of drug-induced interstitial nephritis was made. Furosemide ( $60 \mathrm{mg}$ daily) was prescribed. A history of jaundice, diabetes, uremia, or trauma was denied.

On examination, the patient was an average-built man in grade 2-3 encephalopathy without any localizing neurological deficits. Rest of the general physical and systemic examination was normal. CBC was normal. Serum urea was $48 \mathrm{mg} / \mathrm{dl}$ (normal 10-38) and the creatinine $1.6 \mathrm{mg} / \mathrm{dl}$ (normal 0.6-1.2). Serum sodium was $94 \mathrm{mmol} / 1$ (normal 135-145), serum potassium $2.5 \mathrm{mmol} / 1$ (normal 3.5-5.3), and the chloride $105 \mathrm{mmol} / 1$ (normal 98-110). The serum osmolality was $238 \mathrm{mOsm} / \mathrm{kg}$ (normal 285-295) with a urine osmolality $292 \mathrm{mOsm} / \mathrm{kg}$. Spot urinary sodium was $<10 \mathrm{mmol} / 1$ (normal $>20$ ). ABG analysis and rest of serum biochemistry was normal. The patient was started on $3 \% \mathrm{NaCl}$ till the sodium level reached 120 , when 3\% saline was replaced with $0.9 \mathrm{~N}$ saline. Correction was given at a rate not exceeding $8 \mathrm{mmol} / \mathrm{l}$ day, and serum sodium of 135 was achieved over a period of 8 days. Simultaneously, serum potassium levels were corrected with intravenous potassium chloride [Graph 1]. The patient's consciousness improved dramatically but only to deteriorate again after a 
period of 72 hours with steady deterioration over 24 hours till his speech became incomprehensible and he developed quadriparesis. Neurological examination revealed

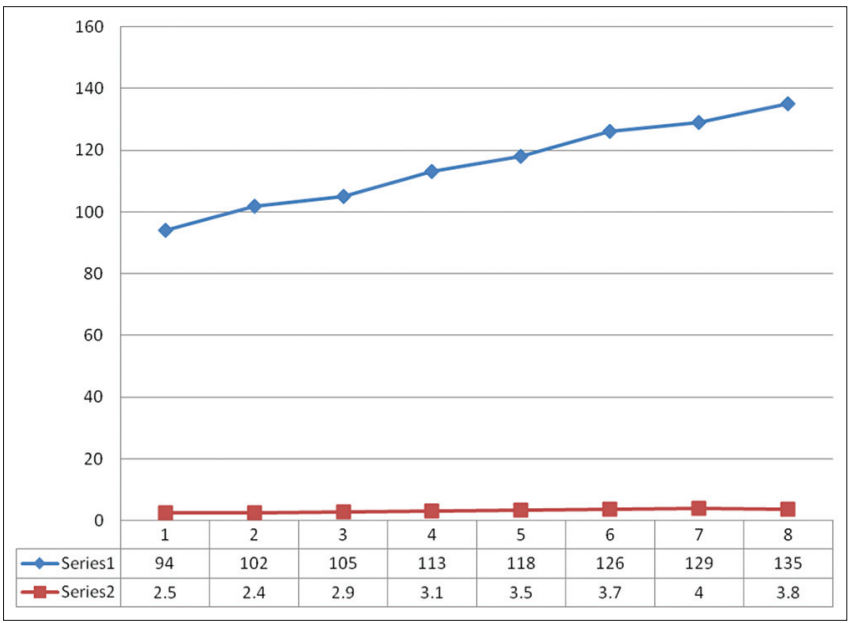

Graph I: Showing rate of correction of sodium and potassium. Series-I depicts highest daily sodium levels and series- 2 represents potassium levels

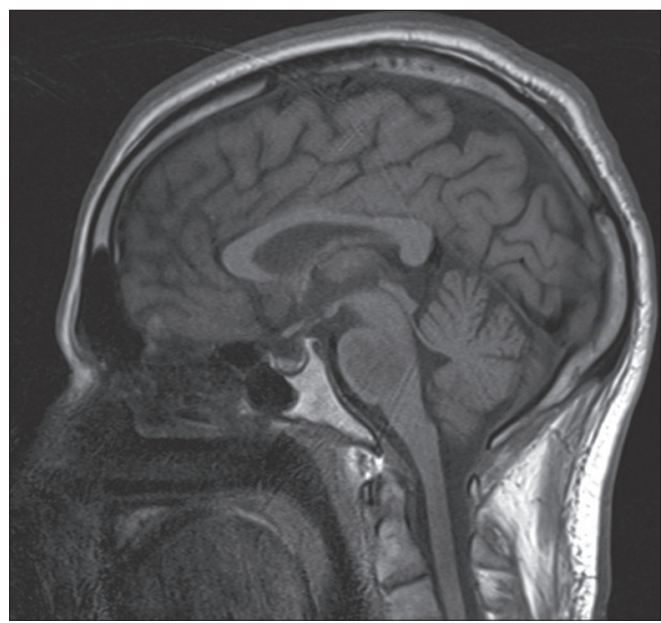

Figure I: Sagittal TIW image showing hypointensity in the pons

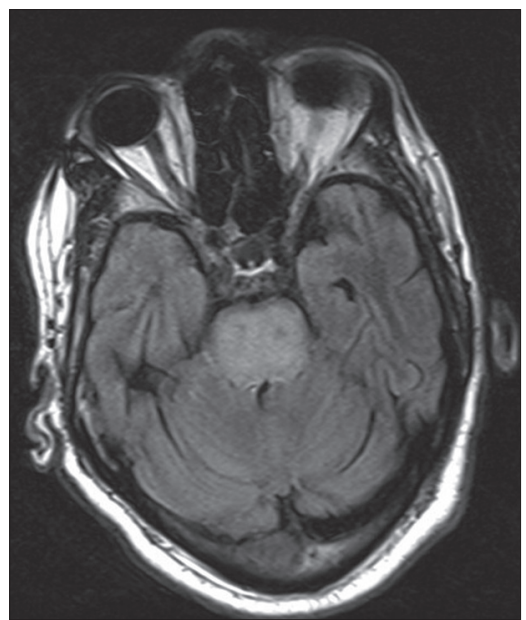

Figure 3: $\mathrm{T} 2 \mathrm{~W}$ image showing diffuse hyperintense signals in the pontine region generalized spastic quadriparesis, mutism and inability to swallow, characteristic of a pseudobulbar state with spontaneous eye opening consistent with the diagnosis of locked-in-syndrome. MRI of the brain revealed symmetrical areas of altered signal intensity in the pons and basal ganglia, being hypointense on T1-weighted imaging [Figure 1] and hyperintense on T2-weighted imaging [Figures 2 and 3 ]. The involved areas were also hyperintense on a fluid inversion recovery (FLAIR) images [Figure 4], suggesting a diagnosis of pontine and extrapontine myelinolysis. The patient received supportive treatment for about a month when he succumbed to intercurrent sepsis.

\section{Discussion}

Our case demonstrates that ODS can develop even after graded correction of hyponatremia. ODS following slow correction of hyponatremia has been reported earlier. ${ }^{[1]}$ First described in alcoholic and malnourished patients who developed neurological symptoms in association with non-inflammatory demyelination within the pons,

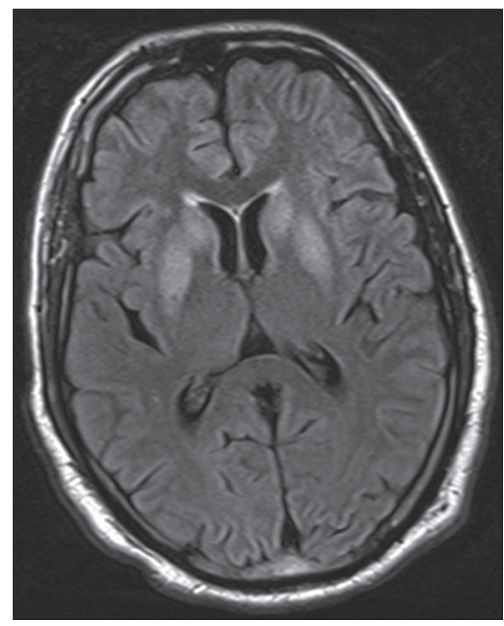

Figure 2: $\mathrm{T} 2 \mathrm{~W}$ image showing symmetrical hyperintense signals in basal ganglia bilaterally

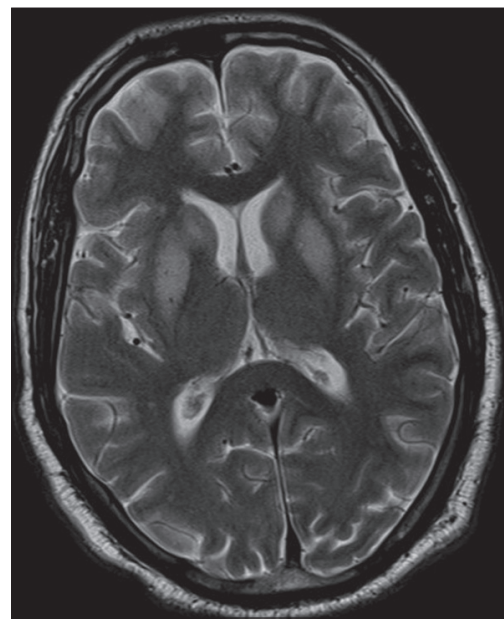

Figure 4: FLAIR image showing hyperintensity in the pons 
the demyelination was then reported in extrapontine areas like basal ganglia, cerebral white matter, peripheral cortex, hippocampi, and lateral geniculate bodies. ${ }^{[2]}$ Seen in up to $10 \%$ cases of ODS, this extrapontine myelinolysis (EPM) mostly involves the basal ganglia and thalamus. ${ }^{[3]}$

Commonly associated with rapid correction of hyponatremia, (rise in sodium level by $>12 \mathrm{mmol} /$ day) the pathogenesis of ODS is not fully understood. It is speculated that in the face of a depleted adaptive process to protect against brain swelling, the redistribution of solutes upon correction of hyponatremia leads to a corresponding brain shrinkage, which leads to disruption of tight junctions and opening of blood brain barrier leading to oligodentrocyte damage triggering the demyelination of neurons. Recently, it has been shown that hyponatremia leads to down regulation of a neutral amino acid transporter that impairs cellular reuptake of amino acids, rendering them more susceptible to injury as hyponatremia is corrected. ${ }^{[4]}$

Patients with osmotic demyelination syndrome typically develop seizures or encephalopathy. As normonatremia is restored, mental status improves and may return to normal within 48-72 hrs, only to rapidly deteriorate days later. Symptoms associated with CPM include dysarthria, dysphagia, flaccid quadriparesis that later becomes spastic, and horizontal gaze paralysis, which is typically followed by coma or delirium..$^{[2]} \mathrm{EPM}$ is characterized by tremor, ataxia, and other movement disorders including mutism, parkinsonism, dystonia, and catatonia. ${ }^{[5]}$

An important accompaniment of the hyponatremia in our patient was hypokalemia [Figure 1]. In a recent study, hypokalemia was found to be a predisposing factor in 7 cases of CPM seen amongst 22 cases of hyponatremia, even when rapid correction of hyponatremia and non-acuteness of hyponatremia were not found to be the risk factors. ${ }^{[6]}$ In another report, $89 \%$ of 74 cases of ODS had associated hypokalemia at presentation that, in contrast to our patient, had not normalized prior to the rapid correction of hyponatremia. ${ }^{[7]}$ Reduced endothelial cell membrane concentration of NaK-ATPase in hypokalemia may predispose the cell to injury by osmotic stress associated with the rapid rise in the serum sodium concentration. ${ }^{[7]}$

Gradual correction of hyponatremia is supposedly the most important step in the management of hyponatremic patients, the rate of correction dictated by the clinical condition of the patient. In asymptomatic patients, plasma
$\mathrm{Na}+$ should be raised very slowly $(0.5-1.0 \mathrm{mmol}$ per $\mathrm{h}$ and up to $10-12 \mathrm{mmol} / \mathrm{L}$ over first $24 \mathrm{hrs}$ ). In patients with altered mental status and/or seizures, a relatively rapid correction (1-2 mmol/L per h for first 3-4 hrs or until seizures stop and up to $10-12 \mathrm{mmol} / \mathrm{L}$ over first $24 \mathrm{hrs}$ ) is recommended. Severe symptomatic hyponatremia can be treated with hypertonic saline. Isolated case reports suggest that steroids, ${ }^{[8]}$ imidazolpyridine tartrate, ${ }^{[9]}$ or plasmapheresis may be helpful in therapy. ${ }^{[10]}$ Patients who survive might require extensive and prolonged neurorehabilitation. In a recent study of 34 patients with ODS, one-third of the surviving 32 recovered, one-third were debilitated but independent, and one-third were dependent. Furthermore, clinical severity or extent of radiological/imaging changes is not predictive of the prognosis. ${ }^{[10]}$

Our case illustrates the development of ODS in graded correction of hyponatremia and emphasizes the possible pathogenetic role of associated hypokalemia.

\section{References}

1. Brown WD. Osmotic demyelination disorders: Central pontine andextrapontine myelinolysis. Curr Opin Neurol 2000;13:691-7.

2. Osborn AG, Salzman KL, Barkovich AJ. Diagnostic imaging: Brain. $2^{\text {nd }}$ ed. Salt Lake City, Utah: Amirsys; 2009

3. Sterns RH, Riggs JE, Schochet SS Jr. Osmotic demyelination syndrome following correction of hyponatremia. N Engl J Med 1986;314:1535-42.

4. Maallem S, Mutin M, Gonzalez-Gonzalez IM, Zafra F, Tappaz ML. Selective tonicity-induced expression of the neutral amino-acid transporter SNAT2 in oligodendrocytes in rat brain following systemic hypertonicity. Neuroscience 2008;153:95-107.

5. Martin RJ. Central pontine and extrapontine myelinolysis: The osmotic demyelination syndromes. J Neurol Neurosurg Psychiatry 2004;75(suppl 3):iii22-8.

6. Heng AE, Vacher P, Aublet-Cuvelier B, Garcier JM, Sapin V, Deteix P, et al. Centropontine myelinolysis after correction of hyponatremia: Role of associated hypokalemia. Clin Nephrol 2007;67:345-51.

7. Lohr JW. Osmotic demyelination syndrome following correction of hyponatremia: Association with hypokalemia. Am J Med 1994;96:408-13.

8. Sakamoto E, Hagiwara D, Morishita Y, Tsukiyama K, Kondo K, Yamamoto M. Complete recovery of central pontine myelinolysis by high dose pulse therapy with methylprednisolone. Nippon Naika Gakkai Zasshi 2007;96:2291-3.

9. Wang WT, Chen YY, Wu SL, Wei TS, Liu SY. Zolpidem dramatically improved motor and speech function in a patient with central pontine myelinolysis. Eur J Neurol 2007;14:e9-10.

10. Grimaldi D, Cavalleri F, Vallone S, Milanti G, Cortelli P. Plasmapheresis improves the outcome of central pontine myelinolysis. J Neurol 2005;252:734-5.

How to cite this article: Koul PA, Khan UH, Jan RA, Shah S, Qadri AB, Wani B, Ashraf M, Ahmad F, Bazaz SR. Osmotic demyelination syndrome following slow correction of hyponatremia: Possible role of hypokalemia. Indian J Crit Care Med 2013;17:231-3.

Source of Support: Nil, Conflict of Interest: None declared. 